\title{
Prevalence of gastrointestinal helminth infections in slaughtered chickens reared in the Nsukka area of Enugu State, Nigeria.
}

\author{
${ }^{1}$ Ngongeh, L. A., ${ }^{2}$ Chiejina, S.N., ${ }^{3}$ Lawal, A.I. \\ ${ }^{1}$ Department of Veterinary Microbiology and Parasitology, College of Veterinary Medicine, Michael Okpara \\ University of Agriculture, Umudike, Abia State, Nigeria, ${ }^{2}$ Department of Veterinary Parasitology and \\ Entomology, University of Nigeria, Nsukka, ${ }^{3}$ Department of Veterinary Parasitology and Entomology, Ahmadu \\ Bello University, Zaria.
}

\begin{abstract}
In order to fully comprehend the possible role of helminth infections of poultry and improve their diagnosis for purposes of effective control and enhance profitable productivity of the ever expanding poultry industry, the prevalence of helminth infections in slaughtered chickens was investigated. A total of 305 gastrointestinal tracts were collected from slaughtered chickens, 177 and 128 of which were from broilers and layers respectively. The intestines were longitudinally incised and the contents washed into cups for the recovery of worms and worm eggs using standard parasitological methods. Results showed that helminth infections were common in the grown birds. Ascaridia galli, Heterakis sp and Raillietina sp were common with the prevalence of 22.3, 0.6 and $6.2 \%$ respectively. However, there was a breed discrepancy in prevalence particularly in A. galli in which layers had a higher prevalence (34.4\%) than broilers (14.1\%). It was concluded that the risk of helminths infections was high in grown birds intensively managed in deep litter in the study area and that it could be the same in similar environments where poultry are managed on deep litter and could compound diagnosis of other health problems of chickens. There is need therefore to regularly screen poultry for presence of helminth parasites particularly when no aetiological agent can be readily incriminated to an impending health or poor productivity of birds and seriously consider their control if present. Such control measures are necessary to subvert depression in production due to the pathogenicity of the parasites which are feasible especially in heavy infections or when the parasites occur concurrently with other infections.
\end{abstract}

Key words: Prevalence, reared on deep litter, slaughtered chickens, proper diagnosis and control

\section{Introduction}

The importance of poultry and poultry products can not be overemphasized as they create employment, provide food and income. Poultry contributes the greatest proportion of animal-source foods (FAO, 2000; Permin and Pedersen, 2010). Agriculture contributes $41 \%$ of the Nigerian gross domestic product (GDP) and poultry is responsible for a great chunk of the $41 \%$ (Encyclopedia of Nations, 2014). Recently poultry was reported to contribute 25\% of Nigeria GDP (AgroNigeria, 2014). Poultry meat and eggs are widely available and relatively affordable. The awareness of poultry and poultry products has increased leading to a tremendous increase in the demand and consumption of the products and such increased market forces have been said to be driving force for expansion of livestock production (Ukagha, 2003). There is a need therefore to sustain the output of the industry at worse and to greatly and rapidly increase it in order to avoid short falls in the expectations from the industry. This no doubt will relieve the stress on many economies by providing more job opportunities and curbing unemployment which is on the rise worldwide. Unfortunately, the efficient productivity of the poultry industry is militated by a lot of factors which include not only the rising feed costs but having to contend with diseases such as helminthosis which though very important is often less emphasized by designers of disease control programmes of poultry and livestock. Helminth infections are common in different poultry production systems and can result to clinical disease as recorded in free range chickens with heavy infections (Ruff, 1999).

Helminth infections can cause production losses through reduced weight gain and weight lost in broilers, poor egg lay in layers and mortalities (Seifert, 1996; Ibrahim et al., 2000). Mortalities caused by parasitic infections in rural chickens are higher than those due to Newcastle disease which is the most common endemic viral disease of poultry (Adene and Dipeolu, 1975). Among the helminth parasites that infect chicken are the gastrointestinal (GI) nematodes notably Ascaridia galli which is said to be more pathogenic in young birds. A. galli is one of the most important helminth parasites of chickens with an incidence as high as $90 \%$ in various countries (Junquera, 2014). Ascaridia infections are reported to be more common in free range than in intensive management (Junquera, 2014). The life cycle of $A$. galli is direct but transport hosts such as earthworms may be involved (FAO Animal Health Manual, 1998). Cestode infections are also common and among the more important ones are Davainea and Rallietina species. Helminths can cause various types and 
degrees of pathology to their hosts either singly or in combination with other pathogens although this is also dependent on the parasite burden.

The pathogenic effects of the parasites on birds can become more severe when the infections occur concurrently with other pathogens some times even at low levels, although it is common knowledge that most helminths cause reasonable pathology when the infections are heavy. However, because of the possibility of a summation effect of the pathology by different pathogens or immune down-regulation of the host immunity by some pathogens/parasites to concurrent infecting parasites, an otherwise in-apparent infection could become manifest. It is thus needful to always make a general assessment of the host health taking into consideration all the possible culprits especially when there is no clear culprit. Such assessments or diagnoses are usually based on the detection of parasite developmental stages mainly egg of the worms in case of helminth infections. Unfortunately, there is not always a good correlation between worm egg counts and WB particularly in A. galli infections where fecundity increase with low WB and decreases with high WB due to host immunological responses (FAO Animal Health Manual, 1998). Therefore, a more efficient diagnosis of A. galli can only be obtained by post mortem worm counts in order to avoid false positives of false negatives. Consequently this study was designed to investigate in a more reliable way the occurrence/prevalence of GI helminth parasites in Nsukka area of Enugu State in eastern Nigeria using slaughtered broiler and layer chickens, thereby also establish the incidence of the infections in grown/adult chickens. Such results would go a long way to inform control measures. To the best of my knowledge and available literature this study is the first of its kind in the area in the exotic breeds of chickens and can thus lay credence or not on antemortem prevalence studies earlier carried out in the area.

\title{
Study location
}

\section{Materials and methods}

The study was conducted at Nsukka abattoir located at Ekpa community market in Nsukka area from July to December, 2013. Ekpa is the official slaughter in Nsukka and is a focus of selling, buying and slaughtering chickens and other animals from towns and villages around Nsukka. Slaughtering is done on daily basis.

\section{Collection and laboratory processing of specimens}

Gastrointestinal tracts (GIT) were collected following slaughter, placed in separate, labelled polythene bags and transported in a cool flask to the Department of Veterinary Parasitology and Entomology laboratory, University of Nigeria, Nsukka on sampling days. The samples were used for the isolation of worms and worm eggs. In the laboratory the intact intestines were dipped in water to rinse off surface contaminants. The entire length of each intestine was incised longitudinally and the contents were emptied into sieves placed in large clean plastic cups. The entire contents of the intestine were washed through the sieve and the filtrate collected in the cups while the worms were recovered from the residue. The filtrate was allowed to stand for 10 minutes to sediment after which they were decanted. The sediments were floated and examined microscopically following centrifugal flotation in saturated sodium chloride solution (Soulsby, 1982, MAFF, 1977) for the presence of worm eggs.

\section{Worm and egg counts}

Faecal worm eggs expressed as eggs per gram (epg) of

faeces, were carried out on intestinal contents from individual chickens using centrifugal flotation in saturated salt (NaCl) solution (MAFF, 1977; Hansen and Perry, 1994). Worm counts were carried out according to Hansen and Perry (1994).

\section{Data analysis}

Data were analysed using Paired-sample Students' T-test. Probabilities of 0.05 or less were considered significant.

\section{Results}

\author{
Worm egg counts \\ Prevalence of GI helminths in different breeds of chickens \\ Worm egg counts
}


Of the 305 chickens sampled, 177 were broilers while the 128 were layers. GI nematodes (predominantly Ascaridia galli), Heterakis and cestodes (Raillietina $\mathrm{sp}$ ) were common in both breeds of chickens (Table 1).

Of the 177 broilers sampled, 21 harboured A. galli adults and 15 them also tested positive for A. galli eggs. Three other broilers had A. galli eggs but no adult parasite was present. Therefore a total of 24 broilers had A. galli infections. One broiler had Heterakis eggs.

On the other hand out of the 38 layers that harboured adult A. galli, 21 also tested positive for A. galli eggs. However, 6 other layers harboured only A. galli eggs, making the number of layers with A. galli infections to be 44 .

The worm burden of layers infected with $A$. galli ranged from 1 to 31 while that of ranged from 1 to72.

Table 2. Prevalence of gastrointestinal helminths in the different breeds of chickens

\begin{tabular}{|l|l|l|l|l|}
\hline Breed of chicken & $\begin{array}{l}\text { Total } \\
\text { examined }\end{array}$ & & Heterakis & Raillietina sp \\
\cline { 2 - 5 } & 177 & Ascaridia & $1(0.6 \%)$ & $12(6.8 \%)$ \\
\hline Broiler & 128 & $38 / 6(34.4 \%)$ & $0(0 \%)$ & $9(7.0 \%)$ \\
\hline Layer & 305 & $68(22.3 \%)$ & $1(0.6 \%)$ & $19(6.2 \%)$ \\
\hline
\end{tabular}

\section{Discussion}

GI helminth infections were common in the birds in the study area. This was established using post mortem worm counts which is more reliable when compared with the FEC which might vary due to false positives or negatives as a result of immune responses to worms by the chickens (FAO Animal health Manual, 1998). However, the GI nematodes especially A. galli were more prominent than the cestodes. There was a breed discrepancy in A. galli prevalence in that it was higher in the layers (34.4\%) than in the broilers $(14.1 \%)$. The high helminth prevalence in the layers in spite of their older ages may be partially contributed to by the poor hygienic status observed in some poultry farms in the area whereby old litter are cleared and replaced with clean dry wood shavings only once or twice in a year and is often wet and caked in some cases due to leakages of drinkers and roofs of the buildings or by splashed water while refilling drinkers with clean fresh water. In fact some attendants usually pour off remnant water in the drinkers while refilling them with clean fresh water. This often lead to a decay of the litter providing a good medium for free living earthworms and the parasitic worms and the resultant ammonia gas is not only directly harmful to the birds but its odours tend to attract various ants which come to feed on the maggots in the decaying litter. These invertebrates can enhance the spread of the worms as trasnsport hosts thereby making the confined environment to function as a sort of open field where free range birds survive. Cestode infections were also found to be a common parasite in the birds with a fair equal distribution within the broilers and layers. The results are significant in that the levels of infection especially that of $A$. galli were reasonably high $(22.3 \%)$ and demonstrated that helminth infections are indeed a common occurrence in adult chickens just in the young chickens often emphasized. Ngongeh et al. (2012) had also reported the prevalence of GI nematode infections in chickens in Umuahia area in Abia State in Nigeria with an overall prevalence of $43.2 \%$ while that of $A$. galli was $21.7 \%$ being very close to that obtained for $A$. galli $(22.3 \%)$ in the current study although the prevalence value in the previous study encompasses both the free range and intensively managed chickens. On the contrary Fakae and Abiade (2003) had reported a very low prevalence of $1.25 \%$ in local chickens slaughtered at Nsukka in Nigeria although the prevalence of cestodes (Raillietina tetragonal) in that study was $92.5 \%$ being much higher than the $6.2 \%$ obtained in this study. Unlike in the current study more species of GI nematode infections were common in the study of Fakae and Abiade (2003) although the study was a rainy season survey. Apart of the risk of high litter contamination, some of the worm burdens were high enough to cause intestinal obstruction and other pathogenic effects in the birds with the consequence of poor production. This could become a more severe situation where concurrent infections with other parasites are common as occurs in field situations. The result is an eye pointer to the danger of mix rearing of young and old birds as the later would infect the young birds through heavy litter contamination. Some of the slaughtered birds were evidently emaciated, although it can not be readily said what could have been the cause, it is possible that helminth infection could have played a role either singly or in combination with other factors. The results also reiterate the need for regular administration of anthelmintic drugs to the birds adults inclusive or other form of helminth control irrespective of their age. However, there would be need to screen chickens for the presence of worm infections before dosing in order to reduce the frequency of treatments so as to reduce the risks of the development of anthelmintic resistance which is a serious threat in the control of parasitic infections. The helminth prevalence obtained here suggests that either 
anthelmintic treatments were not common in the birds or that there is a possibility of presence of anthelmintic resistance in the area.

A. galli infections can be acquired directly by ingestion of infective eggs of A. galli or by the ingestion of transport hosts such as earthworms which contain the second larval stage of $A$. galli in their tissues. A. galli infections are generally known to be more common in free range birds due to the availability of the earthworm mechanical vectors in the fields, but the results presented here warns of the potential threat of the infection in confinement reared birds as well. It is not surprising however given that the bionomic requirements are readily met given that the high tropical temperature is almost constant. Therefore with the availability of adequate moisture which is easily obtained in situations where the poultry house hygiene is poor the infections can thrive. Once the bionomic factors are met and the infection is present in a locality, build up of the infection is ascertained.

It is generally reported that cestode infections of poultry are common only in free range poultry and rare in confined poultry (FAO Animal Health Manual, 1998), but the findings in this study has illustrated that cestodes infections are also common in broiler and layer chicken kept in deep litter in Nsukka area. This is not awesome given that the intermediate hosts of the cestodes namely earthworms, beetles, flies, ants or grasshoppers are near ubiquitous and can easily inhabit pens in confined poultry especially with some moisture in case of earthworms. There is therefore need to seriously consider the control of cestode parasites in intensively managed poultry just as it is being practised against the GI nematodes. The control measures are necessary to subvert depression in production due to the pathogenicity of the parasites which are feasible especially in heavy infections so as to maintain the steady rising output of the poultry industry to meet up with the increasing demands for poultry and poultry products as well as create more employment and minimize the unemployment rate. Helminth infections are thus common in chickens in Nsukka area and are therefore a problem in adult or grown chickens in deep litter system reared chickens.

\section{References}

[1]. Adene, D.F. and Dipeolu, O. O. (.1975) "Survey of blood and ectoparasites of domestic fowls in Ibadan, Western State of Nigeria," Bulletin of Animal Health and Production in Africa. 23: 333-335.

[2]. Encyclopedia of the Nations. (2014). Nigerian agriculture. Available from <http://agronigeria.com.ng/iona-gdp-pan-president/> Retrieved on $17^{\text {th }}$ October, 2014.

[3]. Fakae, B. B.; Paul Abiade, C. U. (2003). Rainy season period prevalence of helminths in the domestic fowl Gallus gallus in Nsukka, Eastern Nigeria. Nigerian Veterinary Journal 24: 21-27

[4]. FAO Animal Health Manual (1998). Epidemiology, diagnosis and control of poultry parasites. Rome.

[5]. FAO. (2000). Statistical Database. Food and Agriculture Organization of the nited Nations. Rome, Italy.

[6]. Hansen, J., Perry, B., 1994. The epidemiology, diagnosis and control of helminth parasites of ruminants. ILRAD, Nairobi, Kenya. Xt, pp. 171.

[7]. Ibrahim, U. I., El-Yuguda, A. D. and Tambari, P. S. (2000). "Traits of feed base New castle disease Lasota Vaccine in chickens using feeds as vaccine vehicles" "Nigerian Journal of Experimental and Applied Biology; 1:20.

[8]. Junquera, P. (2014). Ascaridia spp, parasitic roundworms of poultry, biology, prevention and control. Chicken ascaridiasis. Ascaridia galli, Ascaridia columbae, Ascaridia dissimilis. Retrieved on $1^{\text {st }}$ Octber, 2014 from < http://parasitipedia.net/index.php?option=com_content\&view=article\&id=2647\&Itemid=2923>

[9]. MAFF (Ministry of Agriculture, Fisheries and Food Agricultural Development and Advisory Service). (1977). Manual of Veterinary Parasitological Laboratory Techniques. Technical Bulletin No. 18, HMSO, London,pp 36-37.

[10]. Ngongeh et al. (2012). Prevalence of gastrointestinal parasites in free-ranged and intensively reared chickens in Umuahia area in south eastern Nigeria. Journal of Sustainable Agriculture and Environment. 13: 125-136.

[11]. Permin, A. and G. Pedersen. (2010). Problems related to poultry production at village level. Proceedings of the Possibilities Smallholder Poultry Projects in Eastern and Southern Africa, May 22-25, Morogoro, Tanzania, pp: 65-69.

[12]. AgroNigeria (2014). Poultry is responsible for 25 percent National gross domestic product (GDP). Retrieved on 25/10/2014 from <http://agronigeria.com.ng/2014/10/17/

[13]. Ruff, M.D. (1999). Important parasites in poultry production systems. Veterinary Parasitology. 84:337-347

[14]. Seifert, H. (1996). Tropical Animal Health. KluwerAcademic Publishers, Boston/London.

[15]. Soulsby, E.J.L. (1982). Helminths, arthropods and protozoa of domesticated animals. $7^{\text {th }}$ edition. Balliere Tindal, London.

[16]. Ukagha, E. (2003). Socio - economic constraints. Proceeding of 8th Annual Conference of Animal Science Associal of Nigeria Held at Federal University of Technology,Minna, Nigeria. ppp x-vix. 